\title{
Pacientes, problemas e fronteiras: psicanálise e quadros borderline
}

\author{
Guilherme Geha dos Santos* \\ Gustavo Adolfo Ramos Mello Neto \\ Universidade Estadual de Maringá, Departamento de Psicologia, Maringá, Paraná, Brasil
}

\begin{abstract}
Resumo: 0 artigo trata do quadro clínico conhecido como borderline e é derivado de um exame da literatura psicanalítica sobre o quadro. Nosso objetivo é oferecer informações de maneira sistematizada para que os leitores possam se aprofundar no tema, ou mesmo para que possam confrontar suas posições com as de diversos autores. Trataremos das diversas definições e nomenclaturas, da psicodinâmica, dos sintomas, da etiologia, da diversidade das técnicas terapêuticas, dos problemas comuns durante o tratamento e dos aspectos gerais da transferência e da contratransferência. Ao final, ofereceremos uma contribuição acerca da psicodinâmica, a qual se refere à identificação na literatura da ideia de um objeto borderline que é parte da essência psicodinâmica do quadro. Ademais, desenvolveremos análises das informações examinadas nos utilizando da ideia de objeto borderline como baliza.
\end{abstract}

Palavras-chave: quadros borderline, psicopatologia, psicanálise, estados-limite, objeto borderline.

\section{Introdução}

Os casos borderline, também chamados de estados-limite ou fronteiriços, compõem uma área de investigação científica conhecida pelas dificuldades que esses pacientes apresentam aos profissionais. É possível notar uma forma de atração ou de repulsa imediata a tais quadros, especialmente por aqueles que utilizam a psicanálise em sua prática clínica ou acadêmica, seja em razão das dificuldades no manejo dos pacientes, seja devido à diversidade e falta de coesão da teoria. Por essas razões, realizamos um exame da literatura psicanalítica sobre o quadro borderline (Santos, 2017), que tinha por objetivo dar alguma organização à literatura por meio de uma revisão que abarcasse o início das discussões em torno de casos borderline na década de 1930 até o momento atual.

Apesar de não nos restringirmos aos limites da pesquisa que realizamos, da qual o presente texto é um produto, é necessário informar o leitor daquilo que foi realizado. Com um problema amplo como direção - "O que é um quadro borderline?" -, buscamos trabalhos científicos de autores que, ao nosso entender, partiram de uma questão semelhante. Utilizamos o buscador PsycINFO usando os termos psychoanalysis e borderline disorder. Com esse procedimento encontramos 620 referências de artigos, cujos resumos foram lidos de modo a possibilitar a seleção de textos que tratavam de tentativas de definição ou compreensão geral do que é o quadro borderline e das dificuldades que apresenta seu tratamento. Ao final, selecionamos 45 artigos para análise, cujas datas de publicação se estendem de 1930 a 2016.

Nossa pesquisa teve, pois, um viés histórico, pois comparamos entre si textos de várias décadas. O presente

* Endereço para correspondência: guilherm_santos@hotmail.com artigo não vai fazê-lo, porém, não deixaremos de incluir na revisão os textos mais antigos.

\section{Aspectos gerais da literatura psicanalítica sobre o quadro borderline}

Algo nítido na literatura sobre o quadro borderline é a ausência de uma definição precisa do que seria essa psicopatologia e também a grande variedade de utilizações do termo. Não se pode dizer que a definição das categorias psicopatológicas em psicanálise seja muito precisa, mas o quadro borderline parece ser aquele que mais dificuldades apresenta nesse sentido. Zilboorg (1956), por exemplo, diz que a área da psicopatologia correspondente ao quadro borderline é uma penumbra teórica. Green (1977/1986), por sua vez, diz que essa área corresponde a uma terra de ninguém.

O termo borderline, em sua origem, remete a uma divisão, uma fronteira. Em linhas gerais, na psicanálise, trata-se da fronteira entre a neurose e a psicose. Esse é talvez um dos poucos aspectos consolidados e aceitos no período inicial das investigações. Glover (1932, p. 841), por exemplo, alega que os quadros borderline têm "um pé nas psicoses e outro nas neuroses", algo que ilustra o que dissemos. Não obstante, como veremos, esse fato se tornou discutível quando autores como Kernberg (1967) propuseram a ideia de o quadro borderline ser uma estrutura específica e não um fenômeno misto, ou mesmo de fronteira.

Outro autor que se refere ao borderline como fronteira entre as neuroses e psicoses é Stern, cujo estudo (1938) é conhecido como um dos marcos iniciais

1 As citações de artigos em língua inglesa foram traduzidas por nós de maneira livre. 
da investigação do assunto, descrevendo os sintomas típicos dos pacientes que ele atendia (entre outros, hipersensibilidade, rigidez na personalidade, sentimentos de inferioridade, profunda insegurança e dificuldades no exame da realidade, especialmente voltadas para as relações interpessoais), bem como a necessidade de alterações na técnica psicanalítica clássica para que o tratamento fosse possível.

\section{A disposição entre neuroses e psicoses e as divergências na nomenclatura}

Como dissemos, o quadro borderline, para os primeiros autores, é visto entre as neuroses e as psicoses. No entanto, as definições não são as mesmas desde os anos 1940. São, pois, várias posições que vão surgindo.

Para alguns, por exemplo, o quadro borderline não é nem psicose, nem neurose (Deutsch, 1942/2007; Schmideberg, 1947/1986). Por outro lado, há autores que dizem haver mecanismos neuróticos e psicóticos no quadro borderline (Knight, 1953) - podendo ou não ser uma concordância com a ideia de fronteira. Uma terceira posição que encontramos advém dos autores que propõem para o borderline uma psicodinâmica própria (Bychowsky, 1953; Hoch \& Polatin, 1949; Kernberg, 1966).

Podemos ilustrar essa terceira posição citando Otto Kernberg $(1966,1967,1968)$, autor de grande importância na psicanálise sobre o quadro borderline. Ao desenvolver o conceito de organização borderline da personalidade, ele trouxe coesão e sistematização ao conceito, definindo o transtorno como "não somente estados transicionais, agudos ou crônicos, entre as neuroses, de um lado, e as psicoses, de outro, mas uma forma específica e notável de estrutura egoica patológica" (1966, p. 250).

À medida que os autores dispõem o quadro borderline em diferentes posições em relação às neuroses e às psicoses, a nomenclatura também se diversifica. Ou seja, há uma variedade de termos criados como alternativa a "borderline", que têm por objetivo estabelecer um rótulo diagnóstico mais preciso. Isso é algo notável especialmente nos anos anteriores à década de 1960. Por exemplo, Zilboorg (1941) sugere a expressão "esquizofrenia ambulatorial", pois percebeu nos pacientes que diagnosticou como sendo borderline episódios psicóticos transitórios frequentes.

Por outro lado, é possível notar na literatura psicanalítica críticas a toda essa terminologia ou, melhor, a um excesso de termos que aí pode-se notar. Zetzel (citada por Rangell, 1955), por exemplo, afirma que o termo borderline, em seu tempo, havia se tornado um verdadeiro "depósito de lixo", pois os autores diagnosticavam como borderline uma grande variedade de quadros, abarcando muitos sintomas e desorganizando o conceito.

\section{Psicodinâmica: comportamentos, sintomas, metapsicologia e etiologia}

Nesta seção, iniciaremos apresentando as características do paciente, ou seja, comportamentos específicos, mesmo que não exclusivos, que são agrupados no rótulo diagnóstico de borderline e são manifestados ou interpretados durante o tratamento. Falaremos inicialmente das características ou sintomas relacionados ao sujeito e, depois, de outros dirigidos ao ambiente, seguindo a divisão que percebemos ser feita, em geral, pelos autores.

Comecemos pela agressividade. Ao longo da literatura, esse ponto é tratado como importante e evidente nesses pacientes (Bychowski, 1953; Kernberg, 1967; Zepf, 2012). Zilboorg (1941), por exemplo, fala de uma agressividade que não pode ser contida, o que se assemelha ao que diz de Hoch e Polatin (1949): que as reações de ódio do paciente borderline são muito intensas. Outro elemento observável a respeito da agressividade é aquela voltada para o próprio sujeito. Eisenstein (1951) aponta o alto risco de suicídio, e Bion o faz em relação às ameaças de suicídio. Do mesmo modo, Stone (1992) chama atenção para os comportamentos autolesivos frequentes. Seja como for, tais manifestações são atualmente muito conhecidas, tanto por psicanalistas como psiquiatras ${ }^{2}$.

Outro sintoma importante do quadro seria a falta de identidade (Mitchell, 1985; Rosenfeld, 1978); ou seja, ausência de organização e sensação de continuidade de características que o sujeito entende como suas em aspectos diversos, como desejos sexuais, laborais, entre outros. Esse ponto é examinado em detalhes por Kernberg (1967), também mencionado por Fonagy (1991), quando fala de uma fragmentação no senso de identidade. Para Deutsch (1942/2007), a ausência de identidade é percebida pelos constantes comportamentos de imitação empregados pelos pacientes borderline. Para ela, é como se eles agissem de forma pouco genuína, ou seja, em desacordo com seus desejos.

Um terceiro sintoma que a literatura psicanalítica evidencia é a instabilidade do humor (Fonagy, 1991; Mitchell, 1985; Schmideberg, 1947/1986), especialmente os comportamentos impulsivos (Kernberg, 1966) e imprevisíveis (Fonagy, 1991). Aqui, é possível notar uma convergência com os sintomas descritos anteriormente, uma vez que a ausência de identidade pode ser notada pelo ambiente, fazendo com que os comportamentos do sujeito borderline sejam vistos como imprevisíveis. Além disso, a forte agressividade do borderline poderia incitar os comportamentos impulsivos.

Sobre as características dos pacientes que aparentam ser dirigidas ao ambiente, vamos a elas, destacaremos, em primeiro lugar, a falta de autonomia.

\footnotetext{
2 Como bem assinala Giusti (2013), para o DSM-IV, a automutilação ou autolesão é um dos critérios para o diagnóstico do transtorno de personalidade borderline. Já o DSM-V sugere que os comportamentos autolesivos devam ser classificados numa categoria própria.
} 
Ou seja, o borderline não desenvolveria a capacidade de ser independente (Zilboorg, 1941) ou de tolerar separações (Zetzel, 1971). Para Stern (1938), além da dificuldade nesses pontos, também há um sentimento de inferioridade em relação aos outros.

Entretanto, há um aspecto do quadro borderline, tal como veem alguns autores, que evidencia um tipo de relacionamento interpessoal que deixa claro uma contradição. Para autores como Stern (1957) e Eisenstein (1951), respectivamente, os pacientes apresentam uma forte demanda de amor e de afeto, algo próximo da dependência de que falamos antes; contudo dirigem intensa hostilidade e agressividade à pessoa de quem se sentem dependente (Eisenstein, 1951).

Essa aparente contradição é explicada por Gunderson e Singer (1975/1986), para quem os relacionamentos amorosos dos sujeitos borderline são superficiais com algumas pessoas e intensos com outras. Porém, é Adler (1988) que se aprofunda na compreensão dessa contradição. Ele fala de um dilema necessidademedo, no qual os sujeitos borderline se aproximam muito de um objeto e se tornam dependentes dele. Sentem-se, então, ameaçados, o que pode chegar a um nível intolerável, a ponto de o sujeito abandonar o objeto. Ou seja, precisam e querem se relacionar, mas se sentem ameaçados por sua dependência do objeto.

Deutsch (1942/2007) e Stern (1938) chamam, pois, a atenção para a importância do narcisismo nesse quadro. Algo que é muito enfocado na bibliografia analisada é a respeito da angústia que se pode desvelar nessa patologia. Uma angústia citada como central na patologia borderline é a de aniquilação (Luz, 2010). Frosch (1988) afirma que o conflito básico do borderline é o temor da desintegração. Para Green (2000), essa angústia aparece no medo de se tornar louco, ou mesmo no medo de o sujeito não conseguir proteger os limites de sua individualidade, isto é, de perder suas fronteiras psíquicas.

Interessam também os mecanismos de defesa. Quanto a estes, o que notamos é a ênfase na cisão ou dissociação. Para Rosenfeld (1978), por exemplo, ela é intensa a ponto de gerar estados confusionais, onde partes agressivas atacam partes libidinais do self, o que é projetado no ambiente, tornando-o persecutório para o sujeito dito borderline. Green (1977/1986), por sua vez, afirma que tal cisão, aliada à depressão, explicada como desinvestimento radical, cria estados vazios na mente. Para esse autor, ocorrem nesse paciente duas dissociações: uma entre o psíquico e o não psíquico, e outra dentro do psiquismo, onde são formadas cápsulas isoladas no ego, que ficam sem comunicação (Green, 1977/1986). Por outro lado, Zepf (2012) propõe a ideia de que a cisão é um conceito utilizado pelos psicanalistas como um "jargão", ou seja, é empregado de diversas maneiras, com definições múltiplas, o que diminui seu valor explicativo e sua comunicação.

Seja como for, a ideia de que a cisão está no cerne da psicopatologia borderline é bem importante e é reforçada por outra, a da existência de um germe psicótico, que tem potencial para gerar colapsos psicóticos e funciona como uma parte cindida do ego (Bychowski, 1953). Essa ideia, próxima a de um objeto borderline, será retomada na parte final de nosso artigo.

Sobre a etiologia, o que notamos é a repetição de três ideias principais como explicação para o desenvolvimento do quadro: (1) atinentes a fatores traumáticos, (2) referentes à relação com os pais e (3) concernentes à existência de uma forte agressividade no sujeito. Esses fatores causais não são excludentes, é claro, mas não há autores que falem dos três em conjunto.

A respeito dos traumas na etiologia do quadro, vemos em Greenacre (1941/2010) aparecerem seja como pré ou pós-natais, deixando marcas orgânicas, fonte de angústia. Frosch (1988), por sua vez, é outro autor que menciona traumas na infância, no entanto, mais de quarenta anos antes, Stern (1945) falava de algo um tanto diferente; segundo ele, o sujeito borderline vive em um ambiente traumático, onde não há necessariamente a ocorrência de um grande trauma, mas há, sim, eventos constantes que fazem com que a criança passe a experimentar situações e conflitos cotidianos como se fossem traumáticos.

Sobre a relação com os pais como fator etiológico, Deutsch (1942/2007) fala de fraqueza nas identificações, e Bion (1959/2013) fala da negação, pela mãe, do uso do mecanismo de identificação projetiva, o que impossibilita a comunicação e o vínculo entre mãe e bebê. Adler (1988), por sua vez, de maneira talvez winnicottiana, fala de falhas parentais em compreender as necessidades da criança, que cresce sem segurança interna.

O terceiro fator que mencionamos é o da agressividade. Segundo Bion (1959/2013), no paciente borderline há uma disposição inata ao ódio, destrutividade e inveja em excesso. Zepf (2012), contudo, afirma ser o ambiente que tem ação agressiva sobre a criança, que, estimulada, passa a manifestar a sua própria agressividade.

\section{As técnicas terapêuticas e os problemas durante o tratamento}

Há diferentes abordagens na psicanálise para a condução de casos borderline. De um lado, há autores, como Schmideberg (1947/1986), que afirmam a impossibilidade de empregar a psicanálise em sua forma clássica e recomendam o desenvolvimento de uma psicoterapia especificamente modificada; de outro, há autores que dizem ser necessária uma parte de psicoterapia de apoio e, em seguida, o emprego da psicanálise propriamente dita (Knight, 1953; Stern, 1938). Há, porém, alguns autores, como Bollas (1996), que criticam as psicoterapias por serem uma forma de suporte ao falso self do paciente, pois evitam seu desejo primário, o desejo da turbulência.

Há autores que propõem o emprego da psicanálise sem modificações, mas fazem recomendações que, 
de algum modo, são alterações da conduta clássica. Eisenstein (1951), por exemplo, aconselha evitar situações regressivas. Para isso, sugere a não utilização do divã e da associação livre. Nessa mesma linha, tem-se a proposta de Zetzel (1971), que indica evitar manifestações contratransferenciais ambíguas, pois elas podem promover situações regressivas. Stern (1945), por seu lado, recomenda uma postura mais ativa, pois o silêncio do analista é doloroso.

Sobre as interpretações, Schmideberg (1947/1986) afirma que elas podem causar desconforto e angústia, logo, sua forma seria mais importante que seu conteúdo. $\mathrm{Ou}$ seja, levando em conta a possibilidade das interpretações que causem angústia gerarem a desistência do paciente, essa autora insiste na importância de interpretações que tenham o efeito de reassegurar o paciente. Luz (2009), por seu turno, enfatiza algo que cremos ser muito importante: a necessidade de o analista suportar e sentir a dor do paciente e não apenas compreendê-la, para que, assim, este consiga suportar as interpretações. Para a autora, o analista deve escolher entre proteger o setting ou o paciente; caso se mantenha rígido com respeito às regras do setting, poderá perder informações importantes e, ainda, a análise poderá servir apenas como uma repetição do trauma.

Além de recomendações, encontramos entre os autores anotações importantes acerca dos problemas que ocorrem durante o tratamento. Para Stern (1938), há reações terapêuticas negativas frequentes e escassez de associações. Fonagy (1991) e Green (2000) concordam, pois, com essas afirmações, ao menos no que tange à pobreza associativa. Além desses problemas, diversos autores falam da ocorrência de episódios psicóticos.

Para Greenacre (1941/2010), isso ocorre quando são feitas interpretações precoces da transferência e, em razão de pensar que são causados pelo processo psicanalítico, a autora os chamou "delírios psicanalíticos". Hoch e Polatin (1949), por sua vez, falam de "micropsicoses", que seriam episódios psicóticos curtos e com possibilidade de reintegração e ocorreriam durante a análise. Apesar disso, no texto de Rosenfeld (1978) percebemos a proposta de utilização desses episódios em favor da análise. Para ele, o que ocorre é a psicose de transferência, ou seja, manifestações psicóticas em pacientes não psicóticos. $\mathrm{O}$ autor diz-nos que, durante esse período, as interpretações não têm efeito, porém, apesar de ameaçar o processo psicanalítico, a psicose de transferência não o destrói e pode, inclusive, abrir novos caminhos de análise, por deixar claro os pontos mais traumáticos da vida do paciente.

\section{Transferência e contratransferência}

Como já vimos e como se sabe bem, o paciente de que estamos tratando, através dos autores, apresenta grandes dificuldades na transferência. Falemos, pois, delas.

Para Stern (1948), por exemplo, a transferência do borderline tem aspectos infantis, pré-edípicos, como se se tratasse de uma criança traumatizada. Frente a isso, o autor propõe ao prático evitar situações intensas de angústia, sugerindo o atendimento frente a frente. Para Kernberg (1966), em linhas gerais, o que ocorre na análise de casos borderline é um caos transferencial. Isso acontece, segundo o autor, em razão da cisão patológica que ocorre na psicodinâmica, onde os pacientes do quadro borderline desenvolvem estados egoicos separados, os quais são ativados de maneira oscilatória, gerando manifestações caóticas na transferência (Kernberg, 1966).

Ainda acerca da transferência, é também interessante trazer algo sobre o vínculo entre analista e paciente. Há autores que falam de um vínculo complicado, sobretudo nas décadas iniciais da discussão, mas não somente, como Schmideberg (1947/1986); Zilboorg (1956), por seu lado, fala num vínculo desordenado; e Kernberg (1967) fala de uma ligação simbiótica.

Rosenfeld (1987) de algum modo fala da primitividade do vínculo, quando diz que a identificação projetiva, que ocorre maciçamente no borderline, gera um estado fusionado com o analista, o que pode refletir um desejo de simbiose. Além disso, o vínculo constituído pela identificação projetiva gera um estado no qual o paciente se sente perseguido pelo analista, uma vez que ele projeta no analista os ataques que realiza à sua parte libidinal (Rosenfeld, 1978). Não obstante, a identificação projetiva é uma forma de estabelecer comunicação entre paciente e analista, caso o analista consiga ser continente ao que lhe é projetado (Rosenfeld, 1987).

Outro ponto sobre o vínculo diz respeito ao fato de que o analista se torna fonte de angústia para $o$ paciente. Para Bollas (1996), isso seria uma espécie de vínculo. Bateman (1998), outro autor a falar de um vínculo dessa espécie, sugere que o analista deva se envolver nos terrores do paciente. Por fim, Luz (2009) diz-nos que o analista precisa viver em conjunto com a turbulência do paciente borderline para que uma dupla de trabalho seja construída. Ou seja, levando em consideração a complicação, falta de ordem e a busca de simbiose, que podem ocorrer nesse vínculo, alguns autores propõem ver aí não ataques do paciente visando uma separação da dupla, mas a forma pela qual consegue se vincular.

Outros problemas bem comuns que ocorrem na transferência, segundo Bion (1959/2013), dizem respeito aos ataques à capacidade de pensar do analista, por meio de atuações, atos delinquentes e ameaças de suicídio. Para o autor, esses ataques são fundamentados na inveja sentida pelo paciente pela capacidade do analista de suportar os conteúdos do paciente comunicados via identificação projetiva.

Um problema específico é o da incompreensão das interpretações, dada a predominância da comunicação não verbal (Rigas, 2012). Para Luz (2009), as interpretações transferenciais são insuficientes, pois há intolerância à frustração e incapacidade de simbolizar. Por isso, o "aqui e agora" da sessão é prioritário, assim como as informações obtidas acerca da transferência. 
Um ponto que interessa ainda é o da contratransferência. Winnicott (1947/1994) dá-lhe prioridade ao dizer que o analista precisa estar consciente do possível ódio que sentirá do paciente. Este, desse modo, sentirá que pode ser amado quando souber que pode ser odiado. Eisenstein (1951) recomenda ao analista manter contato com seus próprios conteúdos, pois a análise com pacientes borderline pode gerar irritação.

Por fim, Green (1977/1986) afirma que a contratransferência é uma ferramenta essencial na análise de casos borderline, pois a comunicação não verbal é maciça. Isso já vimos, atrás, quando mencionamos o papel da identificação projetiva nesses casos.

\section{Finalizando: a ideia de um objeto borderline}

Essa ideia, a de um objeto borderline, tomada como essencial na psicodinâmica do quadro, não é nossa, como explicaremos a seguir; é apenas aludida na literatura. O que propomos é o seu desenvolvimento, a partir das informações que acabamos de apresentar. Trata-se, porém, de um início de desenvolvimento, de indicação de algumas linhas para isso.

Começamos a pensar em desenvolver a ideia de um objeto borderline a partir da leitura do texto de Bychowski (1953), em que o autor propõe a ideia de um germe psicótico no sujeito dito borderline, formado por estados precoces que se mantêm intactos devido à ação da cisão. Como já foi dito, o autor conferiu este nome tendo em vista os colapsos psicóticos que por vezes atingiam o paciente. Essa ideia nos incitou a pensar que havia algo na psicodinâmica do quadro borderline que poderia ser-lhe próprio. Buscamos outros autores que falassem de algo semelhante.

Vimos que Glover (1932) fala de como uma porção do exame da realidade do borderline está vinculada à drogadição, enquanto o restante se mantém isolado dessa porção. Em Stern (1945), o que notamos é a ideia de uma deformação no ego do borderline.

Mais adiante, na década de 1950, Bion (1959/2013) fala de um objeto hostil e persecutório no psiquismo do borderline e que destrói seus vínculos. Quem, contudo, menciona diretamente a ideia de um objeto borderline é Bollas (1996), quando trata de um objeto primário, que procura o acidente e se alimenta da turbulência. Para o autor, esse objeto constituiria a parte borderline da personalidade.

Essas ideias, como dissemos, nos incitaram a pensar na possibilidade de haver um objeto borderline. $\mathrm{O}$ que faremos, aqui, enquanto desenvolvimento do conceito é investigar quais fundamentos essa hipótese teria no recorte da literatura que abarcamos.

Sobre a natureza do objeto borderline, separamos duas ideias que nos auxiliam: (1) para Bion (1959/2013), ao se pensar no objeto hostil, deve-se pensar num objeto parcial, visto, este, como uma função e não como estrutura morfológica. Para Bollas (1996, p. 6), "se inerentemente transtornado enquanto infante ou despedaçado pelo ambiente, ou os dois, o objeto primário não é tanto uma possibilidade introjetável, mas um efeito recorrente dentro do self. Como o vento pelas árvores, é um movimento pelo self".

O ponto seguinte que separamos é (2) a angústia: diz respeito a buscar identificar qual conflito essencial, ou mesmo angústia fundamental, estaria ligado ao objeto borderline. Basicamente, a angústia que podemos retirar da literatura psicanalítica como fundamental é a da aniquilação (Green, 2000; Luz, 2010), ou seja, o medo da desintegração (Frosch, 1988) ou fragmentação (Rosenfeld, 1978). Vimos anteriormente que para Bion (1959/2013) o objeto é uma função e, para Bollas (1996), um movimento pelo self. Isso nos leva - nada nos impede -a propor a ideia de que o objeto borderline tem a função (Bion, 1959/2013) de defender o psiquismo dessa angústia. Ou, ainda, é um movimento pelo self (Bollas, 1996) em direção à retirada da angústia da consciência. Com isso, propomos a ideia de o objeto borderline ser um produto de defesas contra o medo de se tornar louco, de perder a identidade, uma vez que a angústia de aniquilação, em termos representacionais e ideativos, se mostra como medo de enlouquecer.

Até o momento, então, a ideia de um objeto borderline se refere a algo precoce, isolado das demais partes do ego e com íntima relação com a angústia de aniquilação. Nesse ponto, podemos nos aprofundar a partir do que alguns autores falam da cisão no quadro borderline. A referência aqui é principalmente a ideia de Kernberg (1966) de que a cisão ocorre entre partes boas e más do objeto, portanto dentro do objeto; assim como a ideia de Green (1977/1986) de que a cisão ocorre nas partes do ego, ou seja, isolando partes do ego entre si. Inspirando-nos nisso, podemos pensar que o objeto borderline pode ser resultado da cisão entre os objetos, o que o torna um objeto parcial, e pode ser isolado dos outros objetos e partes do ego por meio da cisão dentro do próprio ego. Trata-se aqui da defesa de que falamos antes, de cindir o medo de se tornar louco e isolá-lo dos demais conteúdos psíquicos.

A partir disso, torna-se possível investigar os sintomas (ou traços de caráter) principais que são destacados na literatura, assim como buscar saber se eles, de alguma forma, podem ser relacionados à ideia de um objeto borderline. Para tanto, destacaremos os sintomas (ou traços) de instabilidade, impulsividade, agressividade e dependência.

Como dissemos, a instabilidade ou as variações frequentes e rápidas de humor são comuns nos pacientes borderline. A partir da ideia de um objeto borderline, pensamos que a instabilidade se referiria à aproximação de algo em relação a esse objeto - a aproximação poderia despertar a angústia de aniquilação. Dada a forma como o objeto borderline é isolado das demais partes do ego por meio da cisão, a aproximação seria imediata, 
portanto, gerando os comportamentos irruptivos de raiva e desequilíbrio do humor.

Porém, podemos avançar nos sintomas/traços, agora tratando da dependência do sujeito ou da demanda por afeto e amor. A questão que analisaremos aqui é a respeito da possibilidade de o sujeito borderline projetar ou vincular o objeto borderline a alguém, o que conferiria um equilíbrio a sua angústia. Assim, haveria uma forte demanda por afeto e amor, a qual entendemos como demanda por alguém que suporte a vinculação com o objeto borderline, oferecendo solução temporária à angústia. Trata-se aqui de outro aspecto da defesa, ou seja, além de cindir o medo e isolá-lo, expulsá-lo para fora do psiquismo.

Esse ponto nos ajuda a compreender, também, as mudanças constantes de parceiros amorosos que ocorrem frequentemente nos casos borderline. Se pensarmos o vínculo a partir da ideia de projeção do objeto borderline e lembrarmos da impulsividade com que o sujeito borderline age, poderíamos compreender as trocas constantes como fruto de uma frustração (um sentimento de abandono, por exemplo) que é sentida com grande intensidade pelo sujeito e desestabiliza a vinculação do objeto borderline. Dada a impulsividade do sujeito, não é difícil que ele mude de parceiro ou parceira. Mas, não só isso; sabemos desde Freud que a libido é pouco plástica, de forma que a mudança de objeto amoroso é sempre difícil. Isso leva a pensar que as pessoas que facilmente fazem essas trocas investem pouco nesses parceiros ou, ainda, que o investimento é muito mais no objeto interno do que no externo, de forma que o suporte desse objeto, o parceiro ou parceira real, não importa muito. Essa pode bem ser uma característica do objeto borderline, um objeto de projeção, cuja mudança de suporte aparentemente não traz grandes problemas.

Devemos compreender, aqui, a desestabilização como o retorno da ameaça de se tornar louco. Dissemos que o medo de se tornar louco é a forma de o sujeito sentir sua angústia de aniquilação e de fragmentação, ou seja, a possibilidade de o sujeito perder suas fronteiras psíquicas, isto é, saber-se inteiro, reconhecer a si mesmo. Nesse ponto, o dilema necessidade-medo (Adler, 1988) está de acordo com nossa hipótese. Podemos entendê-lo a partir da ideia de que o medo do sujeito de perder suas fronteiras psíquicas está encapsulado e projetado no outro. Em um dado momento, a própria projeção será sentida como dependência, vista a solução temporária que o outro está conferindo. Então, advirão a ameaça e a troca do relacionamento.

Em contrapartida, as relações do sujeito borderline que não envolvem o objeto borderline seriam superficiais, já que não auxiliariam na solução ou equilíbrio da angústia. Com isso, podemos entender a ambivalência (superficiais e intensas) das relações afetivas.

Outro tema que investigamos a partir da ideia de um objeto borderline é o das técnicas terapêuticas. Em primeiro lugar, discutiremos uma recomendação técnica de realizar uma parte de psicoterapia de apoio antes de dar início à análise (Knight, 1953; Stern, 1945). Da mesma maneira que relacionamos alguns sintomas ao objeto borderline, essa parte de psicoterapia de apoio nos parece uma espécie de preparação da dupla para se vincular ao objeto borderline. No entanto, algumas recomendações técnicas parecem evitar o contato com o objeto.

Em nossa pesquisa, alguns autores recomendam a não utilização do divã (Adler, 1988; Eisenstein, 1951; Knight, 1953; Stern, 1945) e outros indicam que não se utilize a associação livre (Eisenstein, 1951; Knight, 1953). Há, também, quem sugira a realização de apenas uma sessão por semana, para que se evite reações negativas ou ambivalentes do paciente (Zetzel, 1971). Apenas essas recomendações técnicas não se referem a um trabalho apenas psicoterápico e não analítico, porém, em conjunto, parecem um direcionamento técnico que evita o trabalho analítico e o contato com o objeto borderline. Desta forma, evitar-se-ia a possibilidade de o borderline projetar seu objeto no analista, restando à psicoterapia a opção de trabalhar com os conteúdos que estariam no entorno do objeto ou que seriam derivados dele.

Um problema que ocorre no campo da técnica e que citamos anteriormente é o da insuficiência das interpretações, em razão da comunicação do paciente borderline ser maciçamente não verbal (Rigas, 2012). Isso nos apoia na ideia de que a comunicação ou a vinculação com o objeto borderline não são feitas verbalmente. Portanto, buscamos na literatura quais outras formas de comunicação seriam possíveis.

Bollas (1996), por exemplo, diz que, quando olhamos apenas para as deficiências do paciente e não para seus desejos, estamos dando suporte a um falso self. Talvez, aqui, fique mais evidente aquilo que falamos, de que a evitação do contato com o objeto borderline implica no contato apenas com o que estaria no entorno do objeto.

Uma autora que analisou com profundidade a questão da vinculação e da comunicação do analista com pacientes borderline é Luz (2009, 2010). Para ela, o analista deve sentir a dor do paciente, não apenas compreendê-la intelectualmente. Além disso, ela entende que os comportamentos do paciente que podem ser vistos como ataques ao analista devem ser enxergados como a possibilidade de expressão de suas dores. Algo que encontramos nos trabalhos dessa autora nos serve de esclarecimento para nossos argumentos sobre a técnica. Para ela, a análise com pacientes borderline se dá em dois níveis: um neurótico, via comunicação verbal, cuja angústia principal é a de castração; e um nível borderline, via comunicação não verbal, cuja angústia principal é a de aniquilação (Luz, 2010).

Um sintoma importante dos casos borderline, do qual deriva um grave problema técnico a que demos destaque no início, é o dos episódios psicóticos. A partir da ideia de um objeto borderline, poderíamos compreender esses episódios como o aparecimento ou a comunicação deste objeto. No entanto, a ideia da psicose de transferência (Rosenfeld, 1978) nos auxilia no aprofundamento deste 
ponto. Para Rosenfeld (1978), a psicose de transferência indicará os pontos mais traumáticos do paciente borderline e, apesar de ser obstáculo à interpretação e à comunicação, ela mostra novos caminhos de análise. Portanto, essas manifestações poderão indicar os conflitos que subjazem aos sintomas do paciente, os quais se englobariam na angústia de aniquilação ou medo de desintegração. Mais uma vez, parece-nos que este ponto reforça a ideia de que as psicoterapias que não abarcam esse conflito ou o objeto borderline ficarão limitadas.

Em resumo, nossa interpretação acerca das questões técnicas apresentadas e aqui rediscutidas é a de que há uma variação de abordagens e recomendações que podem ser agrupadas e balizadas entorno da ideia de um objeto borderline. O que encontramos são três variações, a saber: (1) técnicas que evitam a aparição do objeto ou a vinculação com ele; (2) técnicas em que se faz uma parte de psicoterapia de apoio como forma de preparação da dupla para a vinculação com o objeto; (3) técnicas de análise onde se busca a vinculação com o objeto buscando a elaboração do conflito essencial. O leitor deve notar, ainda, que a forma como as abordagens técnicas estão dividas tem uma evidente relação (quase uma repetição) com os tipos de relação que o sujeito borderline constrói e que já discutimos.

O terceiro e último tema que iremos analisar é o da transferência e contratransferência. Primeiramente, citaremos algumas informações que parecem coadunar com a hipótese de uma transferência em que o objeto borderline não está vinculado, como quando Greenacre (1941/2010) diz que a transferência tem início vazio, ou quando Zetzel (1971) diz que ela é limitada e pobre. Há outros autores, no entanto, que descrevem características que poderíamos interpretar como resultado de algum contato com o objeto borderline, a saber, quando Schmideberg (1947/1986) fala de confusão e estranheza ou Kernberg (1966), que fala de um caos transferencial. Os atributos da transferência que, para nós, refletem o contato com o objeto seriam vistos em Stern (1938), quando ele fala de uma grande dependência do paciente no analista, ou Bion (1959/2013), que fala de pensamentos mágicos em relação ao analista.

Sobre o vínculo, alguns autores e informações que já citamos podem também ser agrupados em torno da ideia de objeto borderline. Para que seja possível se vincular ao paciente, por exemplo, Luz (2009) diz que o analista deve viver as turbulências com o paciente, e Bateman (1998) diz que o analista precisa se envolver nos terrores do paciente. O conceito de identificação projetiva, aqui, nos ajuda a reforçar a ideia de que o objeto borderline poderá ser projetado parcial ou totalmente no analista. Isso poderia gerar um vínculo simbiótico (Kernberg, 1967; Rosenfeld, 1978), no entanto, poderia tornar o analista ameaçador (Kernberg, 1968).

A simbiose com o analista se torna compreensível a partir da ideia de projeção do objeto borderline, uma vez que isso poderia gerar um equilíbrio na dinâmica psíquica. Porém, esse equilíbrio, agora, dependeria também do analista, o que pode explicar a ideia de que ele se torna ameaçador.

Se tomarmos nossas interpretações como base, ou seja, entendermos a dinâmica de interação do analista com o paciente borderline a partir da identificação projetiva, simbiose e da comunicação não verbal, é possível concluirmos que o borderline implica um enigma ao analista, o enigma de se vincular ou não. $\mathrm{O}$ analista, então, escolheria entre não o ajudar, ajudar nos conteúdos do entorno do objeto, ou assumindo os aspectos simbióticos ligados à vinculação com o objeto borderline.

Para nós, a ideia de um objeto borderline não corresponde a uma solução teórica, muito menos uma evidência clínica. Nosso objetivo é oferecer um direcionamento clínico que, apesar de não arbitrar definições ou recomendações técnicas, incita os clínicos a buscar algo propriamente borderline, ou seja, não se satisfazer com a ideia de que este é um paciente confuso, imprevisível e sem solução. O que é possível ver em nosso texto é a ideia de que os pacientes borderline são deslizantes: escorregam sobre os rótulos diagnósticos, ora mais graves, ora mais leves, sobre seus vínculos simbióticos, agressivos e superficiais, e sobre a análise, com surtos de raiva, ataques ao analista, ou se vinculando a ele, em momentos de turbulência. Contudo, principalmente, deslizam sobre suas fronteiras, como alguém que desliza ou patina sobre uma camada fina de gelo, que se quebra sem dar sinal.

\section{Patients, problems and borders: psychoanalysis and borderline cases}

Abstract: The article deals with the clinical condition known as borderline disorder and is derived from an examination of
psychoanalytic literature on the case. Our goal is to provide systematic information so that readers can delve into the subject,
or even so that they can confront their positions with those of various authors. We'll discuss the several definitions and
nomenclatures, psychodynamics, symptoms, etiology, therapeutic techniques, common problems during treatment and the
general aspects of the transference and countertransference. In the end, we'll offer a contribution in the psychodynamics, which
refers to the identification in the literature of the idea of a borderline object that is part of the psychodynamics essence of the
case. In addition, we will analyze the information examined using the idea of borderline object as guideline.

Keywords: borderline cases, psychopathology, psychoanalysis, borderline states, borderline object. 


\section{Patients, problèmes et frontières: psychanalyse et cadres borderline}

Résumé: L'article traite cadre clinique connu sous le nom borderline et est dérivé d'un examen de la littérature psychanalytique sur le tableau clinique. Notre objectif est de fournir des informations de manière systématique afin que les lecteurs puissent s'approfondir le sujet, ou même pour qu'ils puissent faire face à leurs positions avec celles de plusieurs auteurs. Nous aborderons les différentes définitions et classifications, les psychodynamique, les symptômes, l'étiologie, la diversité des techniques thérapeutiques et des problèmes communs au cours du traitement, et les aspects généraux du transfert et contre-transfert. $\mathrm{A}$ la fin, nous offrons notre contribution sur les psychodynamique, qui fait référence à l'identification dans la littérature de l'idée d'un objet borderline qui fait partie de l'essence du cadre psychodynamique. De plus, nous allons développer des analyses des donnés examinées en utilisant l'idée de l'objet borderline comme objectif.

Mots-clés: cadre borderline, psychopathologie, psychanalyse, états limites, objet borderline.

\section{Pacientes, problemas y fronteras: psicoanálisis y cuadros borderline}

Resumen: El artículo trata del cuadro clínico conocido como borderline y se deriva de un examen de la literatura psicoanalítica sobre el cuadro. Nuestro objetivo es ofrecer informaciones de manera sistematizada para que los lectores puedan profundizarse en el tema, o incluso para que puedan confrontar sus posiciones con las de diversos autores. Trataremos de las diversas definiciones y nomenclaturas, de la psicodinámica, de síntomas, de la etiología, de la diversidad de las técnicas terapéuticas y de los problemas comunes durante el tratamiento, y de los aspectos generales de la transferencia y de la contratransferencia. Al final, ofrecemos una contribución nuestra acerca de la psicodinámica, la cual se refiere a la identificación en la literatura de la idea de un objeto borderline que es parte de la esencia psicodinámica del cuadro. Además, desarrollaremos análisis de las informaciones examinadas utilizando la idea de objeto borderline como baliza.

Palabras-clave: cuadros borderline, psicopatología, psicoanalisis, estados limites, objeto borderline.

\section{Referências}

Adler, G. (1988). How useful is the borderline concept? Psychoanalytic Inquiry, 8, 353-372.

Bateman, A. (1998). Thick and Thin-Skinned Organisations and Enactment in Borderline and Narcissistic Disorders. The International Journal of Psychoanalysis, 79, 13-25.

Bion, W. R. (2013). Attacks on linking. The Psychoanalytic Quarterly, 82(2), 285-300. (Trabalho original publicado em 1959)

Bollas, C. (1996). Borderline Desire. International Forum of Psychoanalysis, 5, 5-9.

Bychowski, G. (1953). The Problem of Latent Psychosis. Journal of the American Psychoanalytic Association, 1, 484-503.

Deutsch, H. (2007). Some Forms of Emotional Disturbance and their Relationship to Schizophrenia. Psychoanalytic Quarterly, 76, 325-344. (Trabalho original publicado em 1942)

Eisenstein, V. W. (1951). Differential Psychotherapy of Borderline States. The Psychiatry Quarterly, 25(1), 379-401.

Fonagy, P. (1991). Thinking about thinking: Some clinical and theoretical considerations in the treatment of a borderline patient. The International Journal of Psychoanalysis, 72, 639-656.

Frosch, J. (1988). Psychotic character versus borderline. The International Journal of Psychoanalysis, 69, 445-456.
Giusti, J. S. (2013) Automutilação: características clínicas e comparação com pacientes transtorno obsessivocompulsivo. Tese de doutorado, Faculdade de Medicina da Universidade de São Paulo. São Paulo, SP.

Glover, E. (1932). A Psycho-Analytic approach to the classification of mental disorders. The British Journal of Psychiatry, 78, 819-842.

Green, A. (1986). The Borderline Concept: A Conceptual Framework for the Understanding of Borderline Patients. In A. Green. On private madness (pp. 60-83). London: Karnac Books. (Trabalho original publicado em 1977)

Green, A. (2000). The Central Phobic Position: A New Formulation of the Free Association Method. The International Journal of Psychoanalysis, 81, 429-451.

Greenacre, P. (2010). The predisposition to anxiety II. The Psychoanalytic Quarterly, 79(4), 1075-1101. (Trabalho original publicado em 1941)

Gunderson, J., \& Singer, M. (1986). Defining Borderline Patients: An Overview. In M. H. Stone (Ed.) Essential Papers on Borderline Disorders: One Hundred Years at the Border (pp. 453-474). New York, USA: New York University Press. (Trabalho original publicado em 1975)

Hoch, P., \& Polatin, P. (1949). Pseudoneurotic forms of schizophrenia. The Psychiatry Quarterly, 23(2), 248-276. 
Kernberg, O. (1966). Structural Derivatives of Object Relationships. The International Journal of Psychoanalysis, 47, 236-252.

Kernberg, O. (1967). Borderline Personality Organization. Journal of the American Psychoanalytic Association, 15, 641-685.

Kernberg, O. (1968). The Treatment of Patients with Borderline Personality Organization. The International Journal of Psychoanalysis, 49, 600-619.

Knight, R. P. (1953). Borderline States. Bulletin of the Menninger Clinic, 17(1), 1-12.

Luz, A. B. (2009). Truth as a way of developing and preserving the space for thinking in the minds of the patient and analyst. The International Journal of Psychoanalysis, 90, 291-310.

Luz, A. B. (2010). Ferenczi: Grão-vizir ou enfant terrible. Revista Brasileira de Psicanálise, 44 (2), 17-22.

Mitchell, A. (1985). The borderline diagnosis and integration of self. American Journal of Psychoanalysis, 45, 234-250.

Rangell, L. (1955). Panel Reports - The Borderline Case. Journal of the American Psychoanalytic Association, 3, 285-298.

Rigas, D. (2012). When interpretations are not enough: interactions between the analytic pair, an intersubjective approach. International Forum of Psychoanalysis, 21, 182-188.

Rosenfeld, H. (1978). Notes on the psychopathology and psychoanalytic treatment of some borderline patients. The International Journal of Psychoanalysis, 59, 215-221.

Rosenfeld, H. (1987). Projective identification in clinical practice. In H. Rosenfeld. Impasse and interpretation (pp. 157-189). Abingdon: Taylor and Francis Group.

Santos, G. (2017). O paciente borderline na literatura psicanalítica, de 1930 a 2016. Dissertação de mestrado não publicada, Programa de Pós-Graduação em Psicologia, Universidade Estadual de Maringá, Paraná.

Schmideberg, M. (1986). The Treatment of Psychopaths and Borderline Patients. In M. H. Stone (Ed.) Essential
Papers on Borderline Disorders: One Hundred Years at the Border (pp. 92-118). New York, USA: New York University Press. (Trabalho original publicado em 1947) Stern, A. (1938). Psychoanalytic Investigation of and Therapy in the Border Line Group of Neuroses. The Psychoanalytic Quarterly, 7, 467-489.

Stern, A. (1945). Psychoanalytic Therapy in the Borderline Neuroses. The Psychoanalytic Quarterly 14, 190-198.

Stern, A. (1948). Transference in Borderline Neuroses. The Psychoanalytic Quarterly, 17, 527-528.

Stern, A. (1957). The Transference in the Borderline Group of Neuroses. Journal of the American Psychoanalytic Association, 5, 348-350.

Stone, M. H. (1992). Incest, Freud's Seduction Theory, and Borderline Personality. Journal of American Academy of Psychoanalysis, 20, 167-181.

Winnicott, D. W. (1994). Hate in Counter-Transference. Journal of Psychotherapy Practice and Research, 3(4), 348-356. (Trabalho original publicado em 1947)

Zepf, S. (2012). Do We Need the Concept of "Splitting" to Understand Borderline Structures? The Scandinavian Psychoanalytic Review, 35, 45-57.

Zetzel, E. R. (1971). A Developmental Approach to the Borderline Patient. American Journal of Psychiatry, 127(7), 867-871.

Zilboorg, G. (1941). Ambulatory Schizophrenia. Psychiatry: Journal for the Study of Interpersonal Processes, 4, 149-155.

Zilboorg, G. (1956). The problem of ambulatory schizophrenia. The American Journal of Psychiatry, 113(6), 519-525.

Zilboorg, G. (1957). Further observations on ambulatory schizophrenias. American Journal of Orthopsychiatry, 27(4), 677-682. 